\title{
CUANDO EL PATRIARCADO SOBREVIVE AL APOCALIPSIS: ANÁLISIS DE THE WALKING DEAD (AMC, 2010-)
}

\author{
Delicia Aguado Peláez \\ Universidad del País Vasco / Euskal HerrikoUnibertsitatea
}

Recibido: 24/03/2014

Aceptado: 12/05/2014

\section{Resumen}

Las series de televisión norteamericanas viven un momento de esplendor gracias a la apuesta por la calidad y por su capacidad innovadora. Pero ¿llegan esos aires de cambio a la representación de las relaciones de poder en el seno familiar? Esta es una de las preguntas que marcan este análisis del drama The Walking Dead (AMC, 2010-): una producción perteneciente al género postapocalíptico zombi heredera de esa obsesión por la seguridad tras los atentados de aquel 11 de Septiembre. El presente artículo es una investigación a través de las teorías feministas que demuestra como el sistema de sexo-género se reproduce mediante esa enrocada imagen que atribuye al hombre el rol de producción y defensa mientras que las mujeres quedan atrapadas en la esfera de lo privado. Roles y estereotipos que nos ayudan a construir una imagen de nuestro mundo a través de la pequeña pantalla.

Palabras clave: Comunicación, género, identidad simbólica, roles y estereotipos, series de televisión.

\begin{abstract}
American television series are currently experiencing a new golden era, thanks to their commitment to quality and innovation. But, is this television renaissance impacting the representation of power relations within the family institution? This is one of the questions which centre the present analysis of The Walking Dead (AMC, 2010), a post-apocalypse zombie drama that shows the world's obsession with issues of security in the aftermath of the 9/11 attacks. This study investigates how gender roles in mass media are still based on a binary system that places men as those in
\end{abstract}


charge of security, production and the public space, while women are relegated to the private sphere. The small screen creates and promotes roles and stereotypes which help us build our world.

Keywords: Audiovisual communication, gender, roles and stereotypes, symbolic identity, television series. 


\section{Introducción}

Las series de televisión están viviendo un momento de esplendor con la llamada Tercera Edad Dorada ${ }^{1}$, un boom de dramas que inundan la pequeña pantalla norteamericana de calidad e innovación. Estas producciones, pese a ser ficciones, hunden sus raíces en la realidad y dejan ver parcelas de la misma ayudándonos a comprender, imaginar y también construir todo un entramado simbólico sobre el mundo que nos rodea. Y, como tal, esta etapa no puede ser ajena al momento histórico más trascendental de los EEUU en las últimas décadas: el 11 de Septiembre ${ }^{2}$. La consecuencia más contundente de este ataque terrorista fue el uso del miedo desencadenado tras aquellos atentados por parte del poder político y económico para encumbrar la Seguridad por encima de Derechos y Libertades.

Y, cual dominó, el reinado de la seguridad también trae consigo una serie de impactos en todos los niveles. Uno de ellos es el que Susan Faludi ${ }^{3}$ describe como volver al mito de seguridad americana. Esta quimera interpreta el ataque en clave doméstica, achacando la sensación de vulnerabilidad a un problema de sexos: «El vigor de la nación se ha desinflado por influencia de las mujeres». Un rompecabezas nacional en el que se vuelcan buena parte de los medios de comunicación rescatando al hombre viril definido a través del rol de productor y defensor, mientras las mujeres deben ocupar su tradicional posición en el hogar.

1. Concepción Cascajosa (2005), recogiendo los estudios de Robert Thompson, relaciona las Edades Doradas con épocas de esplendor del drama televisivo estadounidense. La Primera corresponde a las antologías realizadas en directo desde la ciudad de Nueva York durante las décadas cuarenta y cincuenta; la Segunda se encuadra entre los años ochenta y noventa con producciones como Canción triste de Hill Street o Twin Peaks; y la Tercera corresponde al momento actual iniciado por dramas como Los Soprano o El Ala Oeste de la Casa Blanca.

2. Como atestiguan investigaciones como las realizadas por Cascajosa (2003), Dixon (2004); Frezza (2009) o Grandío (2009), entre otras.

3. FALUDI, Susan. La pesadilla terrorista. Miedo y fantasía en Estados Unidos después del 11-S. Barcelona, Anagrama, 2009, p. 267. 
De esta forma, si miramos a la parrilla televisiva desde aquel 11S nos podemos encontrar con que el agente antiterrorista Jack Bauer (Kiefer Sutherland, 24, Fox, 2001-2010, 2014) encarna a la perfección lo descrito por la autora -fuerte, inteligente, capaz de dar su vida por su familia, su patria y, de paso, con facilidad para atraer al sexo opuesto-; cómo Dexter Morgan (Michael C. Hall, Dexter, Showtime, 2006-2013), un asesino en serie, hace de Miami un sitio mejor mientras intenta proteger a las mujeres que pasan por su vida; o como Walter $\mathrm{H}$. White (Bryan Cranston), un hombre que lleva una vida absolutamente normal, se va volviendo malo con la excusa de mantener a su familia en Breaking Bad (AMC, 2008-2013). Ejemplos de series en las que todo el peso recae en personajes masculinos y en las que las mujeres quedan relegadas a un plano secundario y fuertemente estereotipado. Obviamente no todo el panorama está gobernado por este patrón y las mujeres irrumpen cada vez más fuerte con series como American Horror Story (FX, 2011-), Érase una vez (Once Upon a time, ABC, 2011-) Fringe (Fox, 2008-2013) o el remake de $V$ (ABC, 2009-2011). Pero es destacable como, aunque $\mathrm{M}^{\mathrm{a}}$ Isabel Menéndez ${ }^{4}$ reconoce los aires de cambio, destaca el hecho de que:

Los estudios realizados hasta ahora demuestran que sigue siendo hegemónico un discurso que consolida la dicotomía y jerarquía entre sexos, que relega a las mujeres a un protagonismo marginal, que recoge básicamente los estereotipos de género más conservadores y que mantiene la secular invisibilización de las mujeres entendidas como agentes de cambio, autónomas e independientes.

En esta línea, una ficción de interés para analizar si la apuesta por la Seguridad se traduce en una reproducción del sistema sexo-género es The Walking Dead(AMC, 2010-). Y es que gracias a su condición de drama postapocalíptico tiene la libertad creativa de imaginarse una sociedad que se reinventa debido a las circunstancias. Algo que se recrea desde la institución más básica: la familia. Un espacio ideal para estudiar cuál es el tratamiento simbólico de las relaciones de poder aplicando las teorías feministas.

Antes de continuar, destacar que ésta es una serie de televisión inicialmente desarrollada por Frank Darabont que adapta los comics homónimos de Robert Kirkman y Tony Moore. Una producción que se convierte en el programa estrella no sólo de la cadena AMC sino de la televisión por cable, siendo el drama más visto de la misma con una audiencia en continuo crecimiento ${ }^{5}$.

4. MenÉndez, María Isabel. Discursos de ficción y construcción de la identidad de género en televisión. Palma de Mallorca, Edicions UIB, 2008, 22.

5. De los 5,4 millones de espectadores en su capítulo piloto (en EEUU) a los 12,4 millones durante el final de la tercera temporada, como recoge The Hollywood Reporter en: 
El argumento se centra en la vida de Rick Grimes (Andrew Lincoln), un ayudante de sheriff de Kentucky, que despierta de un coma para descubrir que su comunidad ha sido totalmente arrasada por una epidemia de muertos vivientes. Fiel al arquetipo de zombi bosquejado por George A. Romero, la intriga se centra en la lucha por la supervivencia de un pequeño grupo de personas. Una comunidad que debe intentar repeler tanto el ataque de los no muertos como de otras comunidades de humanos que luchan por su propia subsistencia en un mundo postapocalíptico en el que no existen ni Estado ni instituciones ${ }^{6}$.

\section{Metodología}

Esta investigación tiene como objetivo estudiar la representación de las relaciones de poder en el seno familiar dentro de las series de televisión norteamericanas en un contexto marcado por el impacto del 11 de Septiembre. Para ello, se parte de la hipótesis general que afirma que la supremacía de la Seguridad presente en The Walking Dead impacta en la recreación de un sistema de sexo-género. Otras hipótesis específicas son:

- La familia actúa como institución básica de este nuevo mundo; entendiéndola como familia tradicional -nuclear o basada en lazos sanguíneos- así como familia contemporánea -basada en lazos efectivos-.

- La familia articula el orden social funcionando como sistema de control estructural pseudoautoritario -fuertemente jerarquizado, legitimado por el uso de la fuerza y con unos derechos y libertades limitados- y su liderazgo es controlado por el prototípico sujeto político androcéntrico.

- Este patriarcado se sustenta en base a sistemas de dominación simbólica dicotómicos, donde los varones ocupan el espacio público y las mujeres el privado.

La investigación se centra en el estudio de un total de 35 episodios de The Walking Dead que corresponden a totalidad de la Primera (2010, 6 capítulos), Segunda (2011-2012, 13 capítulos) y Tercera temporada (2012-2013, 16 capítulos). Tras un visionado preliminar, se fijan dos grandes dimensiones. Por un lado, las relaciones de poder dentro del grupo. Por otro, las relaciones de dominación entre sexos.

<http://www.hollywoodreporter.com/live-feed/tv-ratings-walking-dead-gives-692262> consultado el 04-06-2014.

6. Cabe advertir que, a partir de aquí, se desvela buena parte de la trama. 
La primera dimensión se centra en la categoría toma de decisiones, atendiendo a una serie de subcategorías con alta presencia a lo largo de toda la serie: descripción del líder (clase social, edad, orientación sexual, procedencia, raza, sexo...), tipo de liderazgo (autoritarismo, comprensión, cuidados, empatía, profesionalidad, oratoria, táctica...), modelo de toma de decisiones (unipersonal, cesión de poder, participativo); forma de mantener el poder (autoritarismo, consenso, luchas de poder, dependencia); grupos de confianza (miembros, perfil físico y psicológico); liderazgos sectoriales (cuidados, emociones, hogar, ocio, momentos de falta de liderazgo, subgrupos).

La segunda dimensión estudia la relación de hombres y mujeres en su distribución espacial pública y/o privada. Se realiza así un perfil físico (edad, apariencia), social (profesión antes del apocalipsis, habilidades sociales, ocupación en el grupo) y psicológico. Este último atendiendo a la reproducción de una serie de roles y pautas sociales relacionados con los siguientes indicadores: acierto; agresividad; amistad; amor romántico; autoridad; causa de la problemática; crueldad; cuidados; defensa, dependencia, desconfianza; desesperación; diálogo; disputas; dominio; emotividad; empatía; error; espera; familia; fraternidad; fuerza; independencia; infravaloración; iniciativa; inteligencia; intuición; irracionalidad; liderazgo; locura; maternidad; miedo; necesidad de protección; profesionalidad; religión; seguridad; sexo; suicidio; sumisión; superficialidad; supervivencia; pacifismo; paternalismo; paternidad; posesión; táctica; tareas del hogar; tareas físicas; uso de armas; violencia; virilidad. Indicadores que servirán para delimitar la división generizada de la realidad.

Todo ello se encuadra en el Análisis de Contenido cualitativo buscando la presencia de las citadas categorías en las 35 unidades de análisis, divididas en un total de 705 escenas (91 en la primera temporada, 278 en la segunda y 335 en la tercera). Así, la necesidad de técnicas que permitan un estudio crítico de la cuestión nos acercan al Análisis Crítico del Discurso para poder profundizar en los mensajes explícitos o latentes desarrollados en el texto audiovisual.

\section{Análisis}

El espectador que apuesta por The Walking Dead se ve transportado a un mundo postapocalíptico que se consume ante una plaga de los llamados caminantes. El Estado ha desaparecido y, con él, cualquier protección o servicio encargado de la seguridad. Los personajes están atrapados en un juego sin salida donde todo el tablero parece estar marcado por la necrosis y la muerte. Y, con la humanidad al borde de la extinción, los que resisten no tardan en enseñar la cara más hobbesiana del contrato social convirtiéndose en una pieza más en la partida de destrucción. 
En este contexto, la serie narra los esfuerzos de un pequeño grupo de desconocidos por mantenerse en pie. Una heterogénea colectividad que aúna diferentes núcleos sanguíneos -padre, madre e hijo; hermanos- así como miembros independientes que se van configurando, tanto a nivel organizacional como emocional, como una gran comunidad autogestionada que se articula como una gran familia. Es decir, un conjunto unido por lazos efectivos que repite rasgos de la familia tradicional patriarcal ${ }^{7}$. Este es, por tanto, el punto de partida de un análisis que estudia la representación de las relaciones de poder en el seno del clan, prestando especial atención a la construcción cultural del sistema de pares sexuados.

\subsection{Liderando el espacio público: la virilidad, fuente de seguridad familiar}

Como ya se ha dicho, tras el apocalipsis zombi el Estado desaparece, abandonando a los antiguos ciudadanos a su suerte. Solo la familia resiste articulando los nuevos pequeños colectivos que pasan a funcionar como un clan que muestra su cara más tradicional. De esta forma, en un momento en el que se vuelve a aquel Estado de Naturaleza teorizado por los contractualistas, se ensalza la sociedad dominada por hombres que ocupan exclusivamente la esfera pública $-y$, con ello, el prestigio y el poder-. A este respecto, Alicia Mirayes $^{8}$ explica como este espacio:

[...] suele estar caracterizado por las leyes, la racionalidad, el acuerdo, los pactos, esto es, por la necesidad de la convivencia pacífica negociada. [...] De acuerdo a estas someras definiciones de público y privado, toda relación que estipula una determinada organización del poder se halla dentro de la esfera pública: el desarrollo económico, los sistemas familiares, las instancias educativas, la concepción del empleo, la condición de ciudadanía al ser instancias reguladoras de poder o generar mecanismos diferenciados de poder en los sujetos son instancias públicas.

De esta forma, los hombres sostienen completamente el liderazgo del grupo: los cuatro grandes líderes que dominan las tres primeras temporadas -Shane Walsh (Jon Bernthal), Rick Grimes, Hershel Greene (Scott Wilson) y Philip Blake, más conocido como El Gobernador (David Morrissey)- se articulan según el perfil del estereotipado sujeto político androcéntrico: varón, adulto, blanco, burgués, heterosexual, occidental y sin discapacidades, como denuncia la perspectiva crítica feminista9. Todos ellos obsesionados por la seguridad

7. Que nos definen autoras como Amorós (1985), Miyares (2003) o Pateman (1995).

8. MiYARES, Alicia: Democracia feminista. Madrid, Feminismos, 2003, p. 61.

9. Como, entre otras, las citadas autoras: Amorós (1985), Miyares (2003) o Pateman (1995). 
y por mantener a salvo a los suyos, lo que justifica cualquier tipo de acto contra terceros -abandonos, asesinatos, torturas,...-y también decisiones límite dentro del grupo. Y es que el autoritarismo se ampara en una mayor rapidez y eficacia en un tiempo en el que la capacidad de actuación parece crucial para garantizar la supervivencia.

Aunque el liderazgo se plantea como natural, lo cierto es que no tardan en surgir tensiones internas protagonizadas por los dos grandes patriarcas del grupo: Shane y Rick. Ambos amigos comparten una serie de habilidades ante la seguridad -formación policial, dotes de mando, manejo de armas- que les hace erguirse como la autoridad moral ante la comunidad. Pero esta disputa también se expresa a través de la pugna por el amor -y la protección- de la misma familia: de Lori Grimes (Sarah Wayne Callies), esposa de Rick y amante de Shane durante el tiempo que creía muerto al primero, y de Carl Grimes (Chandler Riggs), hijo del matrimonio. Una competencia entre dos varones alfas que se ejemplifica en una apuesta por la forma del gobierno -en torno a un mayor o menor uso de la fuerza- pero que termina centrada en el control de Lori.

Su obsesión por la que creía su nueva familia lleva a Shane a actuar de forma totalmente posesiva con una Lori que nada entre dos aguas -llegando incluso a intentar violarla (106 TS-19)-. Una actitud que la convierte en la causa de la problemática y el detonante del conflicto. Y es que la locura creciente de un Shane obsesionado con ella y con su posible paternidad llevan a Lori a susurrar a su esposo las palabras de la discordia entre los dos amigos: «You killed the living to protect what's yours? That's right. Shane thinks I'm his. He thinks the baby's his. And he says you can't protect us, that you're gonna get us killed. He's dangerous, Rick, and he won't stop» (209 Trigger finger). Una situación que termina con Rick asesinando a Shane por el bien y la protección de su familia (213 Beside the Dying Fire).

Así las cosas, el final de la disputa destapa la naturaleza del liderazgo de Rick, así como el paralelismo entre las dos concepciones de familia -el grupo como tal y la nuclear-. Por un lado, el aparente aperturismo de Rick termina con la muerte de su amigo y, lejos de producirse un cambio estructural en la gestión, llega a proclamar, desquiciado, la muerte de la democracia con su «This isn't a democracy anymore» (213 Beside the Dying Fire). Unas palabras que se acompañan de una total pasividad y sumisión por parte del resto de la comunidad que refuerza la figura de líder autoritario y cada vez más errático. Por otro lado, la muerte de Shane abre una brecha en el matrimonio y Rick pasa a despreciar a su esposa por el devenir de los hechos; hasta el punto de 
que una atormentada Lori muere intentando dar a luz a su hija sin conseguir su ansiado perdón (304 The Killer Within).

De esta forma, el control de la familia se liga al control del grupo pues ambos necesitan un líder fuerte que provea víveres y garantice la seguridad. Así que pese a la aparente diferencia de ambos contrincantes -Shane defendiendo autoritarismo y pasión, frente a Rick participación y amor-ambos terminan ejemplificando la misma búsqueda de control y posesión por unos subordinados que los ven como necesarios para su protección, para su supervivencia.

Durante la tercera temporada, se repite la gran confrontación entre dos grandes patriarcas, esta vez líderes de diferentes grupos. La disputa de Rick contra el Gobernador- repite el esquema de dos figuras que, pese a su espiral de depresión y locura, cuentan con la sumisión del resto de la comunidad, absolutamente dependiente. De esta forma, las comunidades se supeditan a un líder altamente personalista -y paternalista- basada en una figura fuerte que controla la información y la toma de decisiones que sólo comparte, en ocasiones, con una pequeña cuadrilla de apoyo. Además, cabe destacar que estos miembros de confianza también se acogen al perfil androcéntrico de sujeto político descrito con anterioridad -Daryl Dixon (Norman Reedus), Gleen Rhee (Steven Yeun),...-, mientras el resto de la gran familia queda a total disposición de las decisiones de la cúpula realizando tareas menores.

Justamente este esquema de hombre como líder y salvador de la comunidad se repite a pequeña escala en el resto del grupo. En un encumbramiento absoluto del varón como rey de la Seguridad, estos son representados con roles productivos y de protección a través de sus profesiones -cazador, policía, veterinario- o habilidades -uso de armas, mecánica, táctica, rastreo- útiles para la supervivencia. Competencias que aplican al día a día ocupándose de tareas como la defensa, el suministro de alimentos o armas, el mantenimiento de los vehículos o trabajos físicos en general... En definitiva, roles con los que participan en la acción y que implican reconocimiento y valoración de la comunidad, legitimándolos para ejercer su dominio. En este sentido, aunque también hay personajes o momentos en los que los hombres son ligados al fracaso o a la torpeza, sus acciones están constantemente relacionadas con amistad, competitividad, fraternidad, fuerza, independencia, iniciativa, inteligencia, liderazgo, seguridad, supervivencia o violencia. Así como habitualmente perfilados con actitud agresiva, cruel y exacerbando su virilidad. En líneas generales podemos decir que la representación masculina en The Walking Dead sigue el patrón del male bread winner model, el tradicional cabeza de familia patriarcal que se encarga del sustento y la protección. De tal forma que el resto de miembros quedan subordinados a su figura y a sus decisiones, 
quedando relegados a tareas menores o ligadas al hogar, algo que se aprecia especialmente en torno a los papeles femeninos.

\subsection{Encerradas en el espacio privado: las mujeres como línea de continuidad}

En el otro lado de la balanza, las mujeres. Recluidas en el espacio privado, ellas son las encargadas de realizar las funciones subordinadas y menos valoradas socialmente atendiendo a la división del trabajo en función del género ${ }^{10}$ : cocinar, hacer la colada u ocuparse de la educación de los niños. En ellas recae el rol reproductivo. Un espacio que Alicia Miyares ${ }^{11}$ define de la siguiente forma:

Por esfera privada se entienden las relaciones que no determinan en absoluto la organización del Estado; la esfera privada está caracterizada por el lenguaje emocional, implica el género de relaciones mediadas por los afectos y los sentimientos negativos o positivos. [...] La intimidad y las creencias al referirse principalmente al estado de los sujetos forma parte de la esfera privada.

Un reparto implícito que se muestra como natural y que es incluso verbalizado por las propias protagonistas mientras que hacen la colada (103 Tell it to the Frogs):

- Jacqui (Jeryl Prescott Sales): I'm beginning to question the division of labor here. Can someone explain to me how the women wound up doing all the Hattie McDaniel work?

- Amy (Emma Bell): The world ended. Didn't you get the memo?

- Carol Peletier (Melissa Suzanne McBride): It's just the way it is.

Pese a estos estallidos puntuales de indignación, la división sexual del trabajo está totalmente arraigada y asumida. Una posición que se justifica como herencia de las capacitaciones adquiridas en su vida anterior. Y es que el pasado profesional de las protagonistas o bien es desconocido, o bien está ligado al hogar y la maternidad o no es de utilidad en este nuevo mundo apremiado por la Seguridad -como Andrea (Laurie Holden) que es abogada-. Además, ninguna destaca por habilidades que son consideradas útiles para la supervivencia, lo que refuerza su relegación a un segundo plano de la acción. Una clara división sexual naturalizada del trabajo muy ligada a la idea de Carol Pateman ${ }^{12}$ de que «la provisión de "trabajo doméstico" es parte del significado patriarcal de la feminidad, de lo que es ser mujer».

10. Como explican Amorós (1985), Miyares (2003) o Pateman (1995).

11. MiYARES, Alicia. Op. cit., p. 61.

12. PAteman, Carol: El contrato sexual. Barcelona, Anthropos, 1995, p. 175. 
Por otro lado, en una sociedad marcada por el peligro a un ataque constante, las mujeres no sólo no ocupan tareas de seguridad, sino que no saben desempeñarlas. Su absoluto desconocimiento sobre el uso de armas deja situaciones tan significativas como las vividas durante el primer gran golpe que sufre la comunidad situada a las afueras de Atlanta. Mientras que Rick, Daryl y Gleen están en la ciudad en una misión, un grupo de caminantes ataca el campamento. Los hombres que quedan defienden el asentamiento atacando a los zombis, mientras ellas se agrupan abrazando a sus hijos o a los seres queridos que yacen muertos, desesperadas e incapaces de actuar. Una vez calmada la situación, la mayor crítica no recae en que hay un grupo de personas que necesita aprender a defenderse, sino por el hecho de que Rick se hubiera ido con sus dos compañeros dejando el campamento sin efectivos (104 Vatos, 105 Wildfire). Un implícito pacto patriarcal que presenta como natural la sujeción de las mujeres a los varones para sobrevivir.

Por el contrario, los papeles femeninos se ligan con una serie de roles que las sumergen aún más en esa esfera de lo privado. Las mujeres se ligan al amor romántico o al sexo; causa de la problemática -como la citada muerte de Shane a manos de Rick-; cuidados -asistencia a enfermos, educación de niños y niñas-; dependencia -necesidad de protección o de suministros-; emotividad -siendo más usual verlas mostrar sus sentimientos-; infravaloración -sus habilidades o actos son menos estimados por el grupo-; irracionalidad -realizando actos impulsivos y sin dotes de estrategia-; maternidad -ligadas al cuidado de los más pequeños o a embarazos-; miedo -derivada de esa falta de capacidad de defensa-; sumisión -acatando ordenes-; pacifismo -defendiendo la solución de conflictos evitando la violencia-; o tareas del hogar. De esta forma, todas ellas quedan excluidas de la acción y de las cuotas de poder. Lo que se justifica por su falta de iniciativa, por el fracaso de sus actuaciones, por su condición de detonante de problemáticas o por su infravaloración. En este sentido, el hecho de alejar a las mujeres de la acción es una constante en las ficciones televisivas estadounidenses, como explica David Caldevilla ${ }^{13}$ :

Puesto que los núcleos familiares quedan representados en la mayoría de ocasiones de acuerdo al estándar de familia nuclear estadounidense (padre, madre y dos hijos como mínimo) y la iniciativa conforma una cualidad intrínseca de los personajes masculinos, una mujer con iniciativa parece suponer una amenaza para el hombre de la casa. Por tanto, la iniciativa, en general, tiende a eliminarse de los personajes femeninos, ya que suele verse con recelo en la sociedad, y viceversa: se retroalimenta esta situación con las

13. Caldevilla, David: «Estereotipos femeninos en series de televisión». Chasqui, 111 (2010), p. 76. 
tramas habituales, dado que todas las representaciones sociales, o bien evitan a las mujeres con iniciativa o bien la acentúan de sobremanera, cargando su actitud con connotaciones negativas.

Además, este dibujo de mujer sumisa e inactiva queda amparada en un rol importante en la recreación de esta nueva sociedad surgida del apocalipsis: la continuidad con el mundo anterior sustentando la normalidad de la comunidad. Y es que ellas son las encargadas de mantener el orden sistémico en un momento de caos y destrucción. Una nueva naturalización del conflicto que llega a verbalizarse en una ilustrativa discusión entre dos de los personajes. Andrea queda impactada tras el anteriormente citado ataque al campamento, donde pierde a su hermana. Tras tontear con el suicidio, decide seguir adelante y aprender a defenderse a través del manejo de armas. El uso de la violencia la legitima para realizar tareas normalmente reservadas a los hombres -defensa, misiones, trabajos físicos...- algo que la acerca al sector masculino pero, a la par, la aleja del femenino -pues abandona las labores del hogar-. Una transformación que despierta tensiones entre Lori y Andrea, como se visualiza en esta conversación en la que la primera le echa en cara no contribuir con el grupo (210 18 Miles out):

- Andrea: I contribute. I help keep this place safe.

- Lori: The men can handle this on their own. They don't need your help.

- A: I'm sorry. What would you have me do?

- L: Oh, there's plenty of work to go around.

- A: Are you serious? Everything falls apart, you're in my face over skipping laundry?

- L: Puts a burden on the rest of us, on me and Carol, and Patricia and Maggie. Cooking, cleaning and caring for Beth. And you... you don't care about anyone but yourself. You sit up on that RV, working on your tan with a shotgun in your lap.

- A: No, I am on watch against walkers. That is what matters, not fresh mint leaves in the lemonade.

- L: And we are providing stability. We are trying to create a life worth living.

- A: Are you kidding me? [...] Playing house, acting like the queen bee, laying down rules for everybody but yourself...

Una disputa entre la defensa de la igualdad entre hombres y mujeres -por parte de Andrea- frente a la complementariedad de hombres y mujeres - de Lori-. Sara Mateos ${ }^{14}$, en su estudio sobre la feminidad normativa, define justamente esta última como una de las siete categorías que conforman la misma. Una visión de los dos sexos que se complementan pero que en «el desarrollo

14. MATEOS, Sara: «Construcción de la feminidad normativa y sujeto político». Investigaciones Feministas, 4 (2013), pp. 307-308. 
del discurso este principio sólo está normado para la mujer, quien posee por naturaleza la capacidad de entrega al otro otorgada por don de la maternidad». Una idea que desplaza a la de igualdad, mucho más conflictiva para el sistema patriarcal.

Esta contraposición de identidades tan claramente sexuadas entre el ser masculino viril y protector y el femenino débil y necesitado de protección encumbra a los hombres en cuotas de poder tales que los llevan a actuar con actitudes paternalistas, e incluso posesivas, con las mujeres del grupo con total naturalidad. Un claro ejemplo de cosificación lo encontramos en otro breve diálogo, esta vez entre dos supervivientes. Glenn, del grupo principal, y Maggie Greene (Lauren Cohan), hija del dueño de la granja donde están instalados, mantienen relaciones sexuales. Cuando Dale Horvath (Jeffrey DeMunn) se entera sólo le pregunta si pensó en cómo se sentiría el padre de la chica y su anfitrión, Hershel, sobre ello. Pese a que Glenn replica que ella tiene 22 años no parece convencer a su compañero (205 Chupacabra).

$\mathrm{Y}$ en esta estereotipación femenina se encuentra también la ausencia de alianzas entre las mujeres. En contra de la fraternidad que se va creando entre los varones, los papeles femeninos quedan fuera de esa correspondencia, quedando sus lazos más ligados estrictamente a sus respectivas familias -hermanas, hijos, maridos-, su espacio natural para la división de sexos. Cabe destacar que se crean vínculos en momentos puntuales, como el enfrentamiento de de un grupo de mujeres al esposo de Carol cuando intenta agredirla (103 Tell it to the Frogs). Aún así, esta escena vuelve a mostrar que el mundo femenino está adscrito al ámbito privado ya que el grupo era conocedor de la existencia del maltrato y, aún así, no se inmiscuía por formar parte del entorno familiar. Lo personal, una vez más, no es político, mientras que en las disputas entre hombres entra habitualmente el líder como mediador o encuentran una solución amigable entre «hermanos».

\subsection{Hacia el patriarcado del consentimiento}

Pero la serie de la AMC sufre un cambio a partir de la mitad de la segunda temporada en el que las mujeres se incorporan a la defensa y a la acción -incluso a la toma de decisiones a partir de la cuarta-, acercándose más al esquema de patriarcado del consentimiento del que nos habla Alicia Puleo ${ }^{15}$. Un sistema de dominación que, frente a la coerción explícita, apuesta por el control simbólico aceptado por las propias sometidas. Siendo, entonces, un

15. PULEO, Alicia: «El patriarcado ¿una organización superada?». Temas para el debate, 133 (2005), pp. 39-42. 
sistema más sutil de opresión. Pero aunque el espectador puede verlas utilizando armas o participando en misiones, lo cierto es que los roles siguen estando claramente basados en aspectos dicotómicos entre lo femenino y lo masculino que mantienen el orden simbólico.

Uno de los personajes más significativos a este respecto es el de Andrea, ya que representa la entre los dos sexos. Por un lado, es la primera en interesarse por el manejo de armas -siempre bajo la autorización y la supervisión de los varones-; lo que la lleva a acaparar una mayor cuota de participación dentro del espacio público -más implicación en la acción, realización de trabajos físicos o incluso en ciertos momentos de liderazgo-. Pero, a su vez, esta evolución va a traer consigo una exaltación de aquellos roles ligados tradicionalmente a las mujeres. Por un lado, su personaje vive una hipersexualización ligada a su vestimenta pero también al sexo y al amor romántico; además se acentúa su papel pacifista -especialmente en la tercera temporada que hace de intermediaria intentando que ambos grupos cesen sus tensiones-; o ligándola al fracaso y la torpeza -disparando a su compañero pensando que era un zombi pese a la advertencia de sus colegas (205 Chupacabra); enamorándose de El Gobernador, sin darse cuenta de qué clase de persona era; no consiguiendo avisar a sus compañeros del ataque de la gente de Woodbury (314 Prey)...-. De esta forma, esta acentuación de ciertos roles tradicionalmente ligados a las mujeres hacen que, pese a su esfuerzo, no consiga el patrón de respeto y éxito que tienen sus compañeros varones, ni logra hacerse un hueco en su fraternidad. Es decir, sus errores están ligados justamente al hecho de haberse inmiscuido en un espacio que no le corresponde, algo que Celia Amorós ${ }^{16}$ achaca a las lógicas compartidas de capitalismo y patriarcado:

«La división sexual del trabajo la margina de la producción y define su lugar limitándola al ámbito de la reproducción. De este modo, su aparición en la esfera de producción reviste un carácter marginal, de asomo, que se plasma en la sobreexplotación, o en la asignación de puestos de trabajo definidos por la provisionalidad, al estar "como de paso», la excepcionalidad -la mujer es aquí la suplente por excelencia-, o por la extrapolación de los roles domésticos en la vida social».

A pesar de todo, su personaje abre la puerta al cambio en el resto del grupo y prepara la llegada para la que va a ser la mujer más activa de la trama: Michonne (Danai Gurira). Su figura indómita se distancia de los roles femeninos y se acerca a los masculinos con valores asociados como amistad, fuerza, independencia, iniciativa, inteligencia, liderazgo, seguridad, supervivencia o

16. Amorós, Celia. Hacia una crítica de la razón patriarcal. Madrid, Anthropos, 1985, p. 250. 
violencia. Si bien, durante la cuarta temporada, se va matizando este papel relacionándolo cada vez más con el mundo de las emociones. Cabe destacar que Andrea y Michonne encarnarán la alianza femenina -entendidas como relación horizontal de cooperación, complicidad e independencia entre mujeres- más marcada de toda la serie hasta el momento. Dos personajes excepcionales que acaparan buena parte de la actividad en la acción de las mujeres, pero que no representan la generalidad. Es decir, hace pensar si su irrupción pueda corresponder más a la búsqueda de un público femenino que a la intención de mostrar otra visión del rol de las mujeres.

\subsection{La familia paradigma: los Grimes}

Hasta aquí se ha analizado el grupo de supervivientes de The Walking Dead entendiéndolo como un gran clan a nivel organizacional, así como emocional. Aún así, los pequeños núcleos familiares repiten sistemáticamente este esquema, un patriarca paternal protege a su esposa y descendientes físicamente y también los intenta controlar psicológica y moralmente. Pero cabe destacar una que ejemplifica, en gran medida, todo lo analizado hasta el momento: la familia de Rick Grimes, el protagonista de la serie, y cuya representación sirve como conceptualización de la familia patriarcal que se ha examinado hasta el momento.

Como se ha explicado, el personaje de Rick es bosquejado como un líder natural. Por un lado, cumple con todas las características del prototípico sujeto político normativo. Por otra, posee numerosas habilidades innatas -don de gentes, entrega, nobleza, oratoria- entremezcladas con aquellas devenidas de su pasado como agente de policía-manejo de armas, táctica. Todo ello hacen que rápidamente se haga con el control de un grupo obsesionado con la seguridad. Pese a sus errores y sus malas decisiones, los miembros lo valoran y lo respetan, llegando a depender absolutamente de él, manteniéndolo en el liderazgo pese a rozar la locura tras la muerte de su esposa.

Por el contrario, Lori asume el papel de «primera dama no oficial»-así la llega a denominar Carol (205 Chupacabra)- ocupándose de las tareas domésticas y del cuidado de los más pequeños, haciendo gala de la idea de complementariedad de géneros mencionada. Lidera el sector femenino y tiene continuas tensiones con Andrea por la forma en la que tienen que actuar las mujeres. Y es que para ella, su rol se basa en dar continuidad con la vida anterior, dotando de estabilidad y normalidad a la comunidad, por lo que rehúsa que el grupo se militarice. Por su parte, Rick comenta las grandes decisiones del liderato a su esposa, quien lo hace reflexionar siempre desde el espacio privado. 
Es decir, tenemos la representación de ambas identidades sexuadas. Por un lado, Rick es el varón protector que se encarga de guiar la comunidad en pro de la seguridad y el sustento del grupo, el líder del espacio público. Por otro, Lori representa la continuidad con el mundo anterior, algo que se representa a través de la inmersión de la mujer en el espacio privado. Un espacio cuyas fronteras son marcadas por la propia idea de familia tradicional. Lori es ante todo madre -maternidad por la que llega a dar su vida ${ }^{17}$-, y esposa -la mujer detrás del gran hombre- y sus acciones siempre se centran en recrear la familia como la única institución estable tras el apocalipsis zombi.

Además, la falta de habilidades para la supervivencia en un mundo postapocalíptico la llevan a la búsqueda de un varón fuerte a su lado. Cuando cree muerto a Rick, Shane ocupará su lugar. Algo que será el comienzo de las tensiones entre dos varones y con dotes de mando que, además, estaban ligados por una amistad. Una fraternidad rota por la propia Lori que representa el gastado perfil de Eris, sembrando la discordia entre ambos hombres. Y de nuevo, la confrontación de papeles femeninos y masculinos totalmente sexuados: control, liderazgo y tutela frente a amor, pasividad y necesidad de protección. Un rol dentro de la familia que se extrapola sucesivamente al resto del grupo.

\section{Conclusiones}

En The Walking Dead se presenta el final del mundo civilizado con la vuelta a un Estado de naturaleza en el que cada uno debe desempeñar su papel para poder sobrevivir. Un nuevo tablero en el que la Seguridad se yergue como la absoluta reina del juego. La principal consecuencia es una sociedad basada en grupos que funcionan prácticamente como la institución más básica: la familia. Pequeños clanes que se dibujan desde una visión absolutamente tradicional donde el colectivo está sujeto a un liderazgo personalista que acapara la toma de decisiones.

Y, en este nuevo estadio, los varones dominan el espacio público ligado a la defensa, a la supervivencia y a la toma de decisiones -con valores añadidos como fuerza, inteligencia, razón...-. Un sistema claramente androcéntrico en

17. Es significativo el hecho de que Lori, cuando descubre que está embarazada, decide provocarse un aborto, incapaz de traer un hijo a un mundo postapocalíptico, poniendo, además, en riesgo al resto del grupo. Aunque se arrepiente en el último momento, tendrá que soportar el enfado de Rick por no haber consultado su opinión al respecto (206 Secrets). Lori morirá dando a luz a su hija debido a que necesitaba una cesárea, al igual que le había pasado con su embarazo anterior. muere intentando dar a luz a su hija, pidiendo a Maggie que la abra en canal para que, al menos, la pequeña sobreviva (304 The Killer Within). 
el que las mujeres quedan relegadas a la esfera de lo privado relacionada con los cuidados, el hogar, las emociones y la maternidad -con significantes como amor, conflictividad, debilidad, infravalorización, irracionalidad, sexualidad, torpeza...-. Esta naturalización del arbitrario sistema sexo-género está muy ligado a uno de los mecanismos de la violencia simbólica de la que hablaba Pierre Bordieu en la que la división de los sexos se objetiviza como parte del orden natural de las $\operatorname{cosas}^{18}$.

Las divisiones constitutivas del orden social y, más exactamente, las relaciones sociales de dominación y de explotación instituidas entre los sexos se inscriben así, de modo progresivo, en dos clases de hábitos diferentes, bajo la forma de hexeis corporales opuestos y complementarios de principios de visión y de división que conducen a clasificar todas las cosas del mundo y todas las prácticas según unas distinciones reducibles a la oposición entre lo masculino y lo femenino. Corresponde a los hombres, situados en el campo de lo exterior, de lo oficial, de lo público, del derecho, de lo seco, de lo alto, de lo discontinuo, realizar todos los actos a la vez breves, peligrosos y espectaculares, que, como la decapitación del buey, la labranza o la siega, por no mencionar el homicidio o la guerra, marcan unas rupturas en el curso normal de la vida; por el contrario, a las mujeres, al estar situadas en el campo de lo interno, de lo húmedo, de abajo, de la curva y de lo continuo, se les adjudican todos los trabajos domésticos, es decir, privados y ocultos, prácticamente invisibles o vergonzosos, como el cuidado de los niños y de los animales, así como todas las tareas exteriores que les son asignadas por la razón mítica, o sea, las relacionadas con el agua, con la hierba, con lo verde (como la escardadura y la jardinería), con la leche, con la madera, y muy especialmente los más sucios, los más monótonos y los más humildes.

Es decir, una desigualdad que se tiende a naturalizar como ilusión del dominio masculino y que se refuerza en la división sexual del trabajo, algo presente en la serie tanto a nivel profesional, como de habilidades y tareas desempeñadas.

De esta forma, la hipótesis de partida -la supremacía de la Seguridad presente en The Walking Dead impacta en la creación de una sociedad conservadora que reproduce un sistema de sexo-género- queda refutada, pese a la evolución hacia un patriarcado más sutil especialmente a lo largo de la tercera temporada. Y es que los protagonistas sufren un enaltecimiento de la virilidad justificado en la obsesión por el paternalismo más absoluto. Virilidad que

18. BORDIEU, Pierre. La dominación masculina. Barcelona, Editorial Anagrama, 2000, p. 45.

Feminismo/s 23, junio 2014, pp. 279-297 
recuerda a aquella que describe Susan Faludi ${ }^{19}$ en La pesadilla terrorista como parte de la reacción cultural a los atentados del 11 de Septiembre en la que se apuesta por expulsar aquel mundo de las emociones que había debilitado el gran poder americano mientras se abre para «la búsqueda de un guardián del hogar». Y, mientras se enfatiza la hombría del protector, las mujeres son encerradas en la invisible jaula de lo privado, un retroceso en la esfera simbólica de la feminidad que nos lleva a reivindicar aquel Lo personal es político...

\section{Referencias bibliográficas}

Amorós, Celia. Hacia una crítica de la razón patriarcal. Madrid, Anthropos, 1985. BORDIEU, Pierre. La dominación masculina. Barcelona, Editorial Anagrama, 2000.

Caldevilla, David: «Estereotipos femeninos en series de televisión». Chasqui, 111 (2010), pp. 73-78.

CASCAJOSA, Concepción: "A través del espejo: el mundo después del 11-S en '24'». Revista Latina de Comunicación Social, 56 (2003) <http://www.ull.es/publicaciones/latina/20035632cascajosa.htm>, consultado el 01/12/13.

— : «Por un drama de calidad en televisión: La segunda edad dorada de la televisión norteamericana». Comunicar: Revista científica iberoamericana de comunicación y educación, 25 (2005) <http://dialnet.unirioja.es/servlet/ articulo? codigo $=2927714>$, consultado el 01/12/13.

ClúA, Isabel (ed.). Género y cultura popular. Bellaterra (Cerdanyola del Vallès): Ediciones UAB, 2008.

De FeliPE, Fernando y GómEZ, Iván. Ficciones colaterales. Las huellas del 11-S en las series 'made in USA'. Barcelona, UOC press, 2011.

DixON, Winston. Film and Television after 9/11.Carbonade: Southern Illinois University Press, 2004.

FALUdi, Susan. La pesadilla terrorista. Miedo y fantasía en Estados Unidos después del 11-S. Barcelona, Anagrama, 2009.

FERnÁndeZ, Marta y MenÉndeZ, María Isabel. «Lo que el ojo no ve: Renovación vs conservadurismo en la ficción audiovisual posterior al 11S», en: Actas III Congreso Internacional Latina de Comunicación, (2011). <http://www.revistalatinacs.org/11SLCS/actas_2011_IIICILCS/024.pdf>, consultado el 05/02/2014.

FREZZA, Gino: «Guerras y postguerras. La visión política del futuro en la ciencia ficción de los cómics, películas y series contemporáneas». Formats, 5 (2009), <http://www.upf.edu/materials/depeca/formats/pdf_/art_dos_espl.pdf>, consultado el 01/12/13.

GRANDÍO, María del Mar: «Riesgo y trauma en la ficción televisiva estadounidense post 11-S: el caso de Héroes». Zer,. 16, pp 51-67 (2011).

19. FALUDI, Susan. Op. cit, p. 186. 
MATEOS, Sara: «Construcción de la feminidad normativa y sujeto político». Investigaciones Feministas, 4(2013), pp 297-391.

MenÉndez, María Isabel. Discursos de ficción y construcción de la identidad de género en televisión. Palma de Mallorca, Edicions UIB, 2008.

MiYARES, Alicia: Democracia feminista. Madrid, Feminismos, 2003.

PATEMAn, Carol: El contrato sexual. Barcelona, Anthropos, 1995.

PUlEO, Alicia: «El patriarcado ¿una organización superada?». Temas para el debate, 133 (2005), pp. 39-42.

- . Filosofía, género y pensamiento crítico. Valladolid, Universidad de Valladolid, 2000. 